\title{
CULTIVO HETEROTRÓFICO DE PHORMIDIUM SP A PARTIR DE SACAROSE HIDROLISADA
}

\author{
T. C., NASCIMENTO ${ }^{1}$; S. F. SIQUEIRA ${ }^{1}$; L. Q. ZEPKA ${ }^{1}$; E. JACOB-LOPES ${ }^{1}$; \\ ${ }^{1}$ Universidade Federal de Santa Maria, Depto. de Tecnologia e Ciência de Alimentos, Av. \\ Roraima, 1000, CEP 97105-900, Santa Maria, Rio Grande do Sul, Brasil
}

E-mail: jacoblopes@ pq.cnpq.br

RESUMO: O estudo teve como objetivo avaliar o cultivo heterotrófico da microalga Phormidium sp. utilizando sacarose hidrolisada como fonte de carbono orgânico em diferentes razões carbono/nitrogênio. A inversão da sacarose ocorreu por hidrólise ácida e as razões carbono/nitrogênio estudadas foram de 20 e 30. Os experimentos foram conduzidos em um biorreator de coluna de bolhas. As condições experimentais utilizadas foram: concentração inicial de inoculo de $100 \mathrm{mg} / \mathrm{L}, \mathrm{pH}$ de 7,6 , temperatura de $30^{\circ} \mathrm{C}$, aeração constante de 1VVM (volume de ar por volume de meio por minuto) e ausência de luminosidade. Os resultados obtidos indicaram que a maior produtividade de biomassa $(35,50 \mathrm{mg} / \mathrm{L} . \mathrm{h})$ e a maior produtividade lipídica $(5,34 \mathrm{mg} / \mathrm{L} . \mathrm{h})$ foram alcançadas a partir da razão carbono/nitrogênio de 20.

\section{INTRODUÇÃO}

O termo microalgas não tem valor taxonômico, engloba microrganismos algais com clorofila e outros pigmentos fotossintéticos (Raven et al., 2001). No entanto sob a denominação microalgas estão incluídos organismos com dois tipos de estrutura celular: estrutura procariótica, com representantes nas divisões Cyanophyta e Prochlorophyta e estrutura celular eucariótica, com representantes nas divisões Chlorophyta, Euglenophyta, Rhodophyta, Haptophyta, Heterokontophyta, Cryptophyta e Dinophyta (Hoek et al., 1995).

As microalgas podem ser cultivadas por sistemas heterotróficos onde ocorre produção de biomassa por conversão de compostos orgânicos, na ausência de energia luminosa ou em sistemas fotossintéticos onde a biomassa é obtida por conversão de dióxido de carbono $\left(\mathrm{CO}_{2}\right)$, na presença de energia luminosa (Pereira et al., 2012). Quando comparado ao sistema fotossintético, o cultivo heterotrófico é mais vantajoso em relação aos custos e produção de biomassa, que é a força motriz deste sistema (Choix et al., 2012).

Conforme Wen e Chen (2003) um organismo utilizado para produção heterotrófica deve possuir as seguintes características: habilidade para se dividir e metabolizar na ausência de luz; capacidade para resistirem a stress hidrodinâmico na fermentação; facilidade para se adaptar rapidamente em novos ambientes e possibilidade de crescer em meio de baixo custo.

Estudos recentes mostram que as culturas heterotróficas microalgais estão ganhando interesse crescente para a produção de uma grande variedade de metabolitos em todas as 
escalas (Yang et al., 2000, Wen e Chen, 2003). Nesta condição de cultivo a produção destes bioprodutos (ácidos graxos poliinsaturados, carotenóides, ficobilinas, polissacarídeos entre outros) é economicamente útil, dado reduções significativas na complexidade dos bioprocessos e dos custos operacionais (Tuchman, 1996). Onde uma das razões é o consumo de fontes de carbono simples, barato e disponível como a glicose, acetato, glicerol, sacarose, entre outros.

O custo final da produtividade de biomassa é a característica essencial para os sistemas de cultivo e depende essencialmente das condições e do meio de cultivo (Borowitzka, 1992). Em vista disso uma alternativa para aumentar a redução deste custo é a utilização de sacarose como fonte de carbono orgânico, uma vez que a glicose, a principal fonte utilizada possui alto valor comercial. No entanto a ausência da invertase em algumas espécies de microalgas torna a hidrólise da sacarose uma etapa primordial para o desenvolvimento do processo (Perez-Garcia et al., 2011).

\section{OBJETIVO}

O estudo teve como objetivo avaliar o cultivo heterotrófico da microalga Phormidium sp. utilizando sacarose hidrolisada como fonte de carbono orgânico em diferentes razões carbono/nitrogênio.

\section{MATERIAIS E MÉTODOS}

\subsection{Microrganismo e condições de cultivo}

A cianobactéria utilizada foi a Phormidium sp., isolada do Deserto Cuatro Cienegas no México $\left(26^{\circ} 59^{\prime} \mathrm{N} 102^{\circ} 03 \mathrm{~W}\right)$. Após purificação, as culturas estoque foram mantidas em tubos de ensaio com meio sintético BGN (Rippka et al., 1979) solidificado com agar-agar. As condições de manutenção usadas foram $25^{\circ} \mathrm{C}$ e intensidade luminosa constante de $1 \mathrm{klux}$.

\subsection{Hidrólise da sacarose}

A inversão da sacarose ocorreu por hidrolise ácida, através adição de $0,4 \%$ de HCL $3 \mathrm{M}$ a uma solução de 500 g.L-1 de sacarose, com posterior aquecimento em banho-maria a $80^{\circ} \mathrm{C}$ por 30 minutos e posterior resfriamento até a temperatura ambiente. A neutralização do pH se deu por adição de uma solução de $\mathrm{NaOH} 3 \mathrm{M}$, na mesma proporção do ácido.

\subsection{Meio de cultura}

Utilizou-se o meio sintético BGN para diluição e suplementação de nutrientes inorgânicos. A composição química do BGN é: $\mathrm{K}_{2} \mathrm{HPO}_{4}\left(0,03 \mathrm{~g} . \mathrm{L}^{-1}\right), \mathrm{MgSO}_{4} \quad\left(0,075 \mathrm{~g} . \mathrm{L}^{-1}\right)$, $\mathrm{CaCl}_{2} \cdot 2 \mathrm{H}_{2} \mathrm{O}\left(0,036 \mathrm{~g} \cdot \mathrm{L}^{-1}\right)$, citrato de amônio e ferro $\left(0,0006 \mathrm{~g} . \mathrm{L}^{-1}\right), \mathrm{Na}_{2} \mathrm{EDTA} \quad\left(0,001 \mathrm{~g} . \mathrm{L}^{-1}\right)$, $\mathrm{NaCl}\left(0,00072 \mathrm{~g} \cdot \mathrm{L}^{-1}\right)$, ácido cítrico $\left(0,0006 \mathrm{~g} . \mathrm{L}^{-1}\right), \mathrm{Na}_{2} \mathrm{CO}_{3}\left(1,5 \mathrm{~g} . \mathrm{L}^{-1}\right)$, metais traços: $\left[\mathrm{H}_{3} \mathrm{BO}_{3}\right.$ $\left(0,0028 \mathrm{~g} \cdot \mathrm{L}^{-1}\right), \quad \mathrm{MnCl}_{2} \cdot 4 \mathrm{H}_{2} \mathrm{O} \quad\left(0,0018 \mathrm{~g} \cdot \mathrm{L}^{-1}\right), \mathrm{ZnSO}_{4} \cdot 7 \mathrm{H}_{2} \mathrm{O} \quad\left(0,00022 \mathrm{~g} \cdot \mathrm{L}^{-1}\right), \quad \mathrm{Na}_{2} \mathrm{MoO}_{4} \cdot 2 \mathrm{H}_{2} \mathrm{O}$ $\left(0,00039 \mathrm{~g} . \mathrm{L}^{-1}\right), \mathrm{CoSO}_{4} \cdot 6 \mathrm{H}_{2} \mathrm{O}\left(0,00004 \mathrm{~g} . \mathrm{L}^{-1}\right)$. Empregou-se sacarose hidrolisada como fonte de carbono orgânico exógeno em diferentes concentrações afim de se obter as razões carbono/nitrogênio de 20, 30 e 40. 


\subsection{Biorreator e condições experimentais}

Os experimentos foram realizados em biorreator de coluna de bolhas construído de vidro borossilicato, com um volume total de trabalho de 2,0L. O sistema de dispersão de ar consiste em um difusor localizado no interior do frasco. A vazão de ar foi controlada por rotâmetros (precisão $\pm 5 \%$ ), a entrada de oxigênio e a saída dos gases foram filtradas através de unidades filtrantes Millex-FG ${ }^{\circledR}$, em polipropileno com membrana fluoropore de $0,22 \mu \mathrm{m}$ de diâmetro e $50 \mathrm{~mm}$ de diâmetro total. As condições de cultivos foram: concentração celular inicial de $100 \mathrm{mg} / \mathrm{L}, \mathrm{pH}$ de 7,8 , temperatura de $30^{\circ} \mathrm{C}$, aeração de $1 \mathrm{VVM}$ (volume de ar por volume de meio por minuto) e ausência de luminosidade.

\subsection{Análise lipídica}

A biomassa foi separada do meio de cultivo por decantação, seguido de centrifugação. Posteriormente, a pasta obtida foi seca em estufa com ventilação a temperatura a $60^{\circ} \mathrm{C}$.

Para a extração de lipídeos totais da biomassa, foi utilizado o método de Bligh e Dyer (1959) modificado, levando-se em conta as proporções entre os solventes metanol e clorofórmio, e água destilada (2:1:0,8). Os lipídios da biomassa seca foram extraídos após secagem e trituração em almofariz. A quantidade de lipídeos foi determinada por gravimetria a partir do extrato total de clorofórmio, evaporando-se o solvente e posteriormente secagem em estufa até se obter peso constante.

\subsection{Amostragem e análise dos dados cinéticos}

As amostragens foram realizadas de forma asséptica a cada 24 horas durante a fase de crescimento do microrganismo. A concentração celular e a quantidade de lipídeos foram determinadas através de gravimetria. Os dados de biomassa foram utilizados na obtenção da velocidade máxima específica de crescimento $\left(\ln \left(\mathrm{X} / \mathrm{X}_{0}\right)=\mu_{\max } \mathrm{t}\right)$, onde $\mathrm{X}$ é a concentração celular final $\left(\mathrm{mg} . \mathrm{L}^{-1}\right), \mathrm{X}_{0}$ é a concentração celular inicial $\left(\mathrm{mg} . \mathrm{L}^{-1}\right), \mu_{\max }$ é a velocidade máxima específica de crescimento $\left(\mathrm{h}^{-1}\right)$ e $\mathrm{t}$ é o tempo (h), no cálculo da produtividade de biomassa $\left(\mathrm{P}_{\mathrm{X}}=\mu . \mathrm{X}\right)$. $\mathrm{O}$ teor lipídico alcançado foi utilizado para obtenção da produtividade do mesmo ( $\mathrm{PL}=$ PX.Lipídios/100), onde Lipídios representa a quantidade lipídica em porcentagem. Os experimentos foram realizados em duplicata e os dados cinéticos referem-se a média de quatro repetições

\section{RESULTADOS E DISCUSSÃO}

A Tabela 1 apresenta os parâmetros cinéticos obtidos para o cultivo heterotrófico da cianobactéria Phormidium utilizando sacarose hidrolisada como fonte de carbono orgânico em diferentes razões carbono/nitrogênio. 
Tabela 1- Parâmetros cinéticos da cianobactéria Phormidium sp. através do cultivo heterotrófico com sacarose hidrolisada.

\begin{tabular}{cccccc} 
Razão CN & $\mu$ máx (h-1) & Xmáx (mg.L $\left.{ }^{-1}\right)$ & PX (mg/Lh) & Lipideos (\%) & PL (mg/L.h) \\
\hline 20 & 0,0175 & 5213 & 35,50 & 15,06 & 5,34 \\
30 & 0,0133 & 4763 & 32,38 & 13,89 & 4,49
\end{tabular}

$\mu_{\text {máx }}$ : velocidade máxima específica de crescimento, $\mathrm{X}_{\text {máx }}$ : concentração celular máxima, $\mathrm{P}_{\mathrm{x}}$ : produtividade de biomassa; $\mathrm{P}_{\mathrm{L}}$ : produtividade lipídica.

O cultivo empregando a razão carbono/nitrogênio de 20 apresentou maior velocidade máxima específica de crescimento $\left(0,0175 \mathrm{~h}^{-1}\right)$, maior produtividade de biomassa $\left(35,50 \mathrm{mg}\right.$. $\mathrm{L}^{-}$ $\left.{ }^{1} \cdot \mathrm{h}^{-1}\right)$, melhor desempenho na obtenção de biomassa $\left(5213 \mathrm{mg} \cdot \mathrm{L}^{-1}\right)$, além de maior conteúdo lipídico $(15,06 \%)$ e produtividade lipídica $\left(5,34 \mathrm{mg} \cdot \mathrm{L}^{-1} \cdot \mathrm{h}^{-1}\right)$.

Estes resultados foram semelhantes, porém não superiores aos obtidos por Acosta et al. (2012) ao utilizarem sacarose hidrolisada no cultivo heterotrófico da Clhorella vulgaris, onde os máximos valores de concentração celular e produtividade foram, respectivamente, $5300 \mathrm{mg} . \mathrm{L}^{-1}$ e $41 \mathrm{mg} \cdot \mathrm{L}^{-1} \cdot \mathrm{h}^{-1}$. Fato que pode estar associado à forma de assimilação de cada microalga.

Sun et al. 2008, utilizaram diferentes fontes de açúcar para avaliar o crescimento da Clhorella zofingiensis, onde a sacarose apresentou-se entre as fontes menos eficientes. A concentração celular para essa fonte foi $50 \%$ menor que para glicose, onde se obteve maior crescimento. Essa ineficiência da sacarose esta associada à ausência da enzima invertase em algumas espécies de microalgas, na sua ausência a microalga não assimila corretamente a complexa molécula de sacarose, tornando a hidrólise da sacarose uma etapa primordial para o desenvolvimento do processo.

\section{CONCLUSÃO}

Os resultados obtidos demostraram que razão carbono/nitrogênio de 20 foi a melhor condição para o cultivo heterotrófico de phormidium sp., proporcionando a obtenção de produtividade em biomassa de 35,50 $\mathrm{mg} / \mathrm{L} . \mathrm{h} . .$.

\section{REFERÊNCIAS BIBLIOGRÁFICAS}

ACOSTA F. L., HONORATO L. T., FRANCO, T. T. Cultivo heterotrófico de microalga chlorella vulgaris cpcc90 utilizando sacarose hidrolisada como fonte de carbono orgânico. Faculdade de Engenharia Química - UNICAMP. Lab. Engenharia Bioquímica, Biorrefino e Produtos de Origem Renovável - LEBBPOR. Campinas - SP - Brasil. 
BOROWITZKA, M. A. Algal biotechnology products and processesmatching science and economics. J. Appl. Physiol., v. 4, p. 267-279, 1992.

BLIGH, E.G., DYER, J.W. A rapid method of total lipid extraction and purification. Can. J. Biochem. Phys. 37, p.911-917, 1959.

CHOIX, F. J., DE-BASHAN, L. E., BASHAN, Y. Enhanced accumulation of starch and total carbohydrates in alginate-immobilized Chlorella spp. induced by Azospirillum brasilense: II. Heterotrophic conditions. Enzyme. Microb. Tech. 51, p.300-309, 2011.

HOEK, C. van den et al. Algae: an introduction to phycology. London: Cambridge University. p. 623, 1995.

PEREIRA, P.M.C., HOBUSS, B.C., MACIEL, V.J., FERREIRA, R.L., DEL PINO, B.F., MESKO, F.M., JACOB-LOPES, E., NETO, C.P. Biodiesel renovável derivado de microalgas: Avanços e perspectivas tecnológicas. Quím. Nov., Vol. 35, nº 10, p. 2013-2018, 2012.

PEREZ-GARCIA, O. ESCALANTE, E. M. F., BASHAN E., L., BASHAN, Y. Heterotrophic cultures of microalgae: Metabolism and potential products. Water Res., 45(1): p. 11-36, 2011.

RAVEN, P.H., EVERT, R.F., EICHHORN, S.E., 2001. Biologia vegetal. 6.ed. Rio de Janeiro: Guanabara Koogan, p. 906, 2001.

RIPPKA, R., DERUELES, J., WATERBURY, J. B., HERDMAN, M., STANIER, R. Y. Generic assignments strain histories and properties of pure cultures of cyanobacteria. J. Gen. Microbiol. 111, p.1-61, 1079.

SCHMIDT, R.A., WIEBE, M.G., ERIKSEN, N.T. Heterotrophic high cell-density ed-batch cultures of the phycocyaninproducing red alga Galdieria sulphuraria. Biotechnol. Bioeng. 90, p. 77-84, 2005.

TUCHMAN, N. The role of heterotrophy in algae. In: Stevenson, R.J., Bothwell, M., Lowe, R.L., Algal Ecology. Freshwater Benthic Ecosystems. Academic Press, San Diego, CA, USA, p. 299-319, 1996.

WEN, Z.-Y., CHEN, F. Heterotrophic production of eicosapentaenoic acid by microalgae.

Biotechnol. Adv. 21, p. 273-294, 2003.

YANG, C., HUA, Q., SHIMIZU, K. Energetics and carbon metabolism during growth of microalgal cells under photoautotrophic, mixotrophic and cyclic light-autotrophic/ darkheterotrophic conditions. Biochem. Enging. J. 6, p. 87-102, 2000. 